\title{
Máscaras Sociais: Uma Reflexão Sobre Os Recursos Que O Indivíduo Utiliza Para Proteger Sua Identidade No Contexto Organizacional
}

\author{
Social Masks: A Reflection On The Resources That The Individual \\ Uses To Protect His Identity In The Organizational Context
}

Lindaura Vieira1', Fernando José Lopes², Monica Maria Martins de Souza³

\begin{abstract}
1 - Lindaura Vieira é Psicóloga Pós-graduação em Psicologia Organizacional Pós-Graduando em Neuropsicologia. Psicóloga Clínica e Organizacional Consultora, especialista em Treinamentos, Palestras e Workshop. Em Avaliação Neuropsicológica e Psicodiagnóstico, Wellness Coaching, Depressão, Fobias, Stress, Ansiedade, Sexualidade, Dificuldade de Aprendizagem. E-mail: lindapsicologa@hotmail.com 2 - Fernando José Lopes é mestre em Cognição e Semiótica PUC-SP, pós-graduado em Gestão de Pessoas na Universidade
Paulista, graduado em Administração e Professor das Faculdades Integradas Campos Salles - FICS nas áreas de Gestão e Graduação em
Administração e Ciências Contábeis. Professor convidado dos cursos de pós-graduação em Psicologia Organizacional e Departamento
Pessoal na Universidade Paulista - UNIP. E-mail: lopesfj2008@gmail.com
\end{abstract}

3 - Monica Maria Martins de Souza é Jornalista, psicóloga Clínica Educacional, Organizacional, Dr ${ }^{a}$ em comunicação e semiótica, Psicóloga Mestre em Administração, Especialista em Tecnologia da educação, em Recursos Humanos e em Educação com ênfase em EAD/SP. Editora de Revistas Acadêmicas, Prof e Pesquisadora de Pós-graduação Mackenzie, UNIP, ENIAC - Guarulhos SP e Faculdades Campos Salles.E-mail prmonica@gmail.com

\section{Resumo}

O presente artigo visa propor uma reflexão sobre os recursos que o indivíduo utiliza para proteger sua identidade no contexto organizacional. A metodologia foi o recorte e análise de artigos científicos. A pesquisa aqui apresentada tem caráter bibliográfico. A proposta foi uma pesquisa qualitativa, dentro de uma abordagem psicossocial, ou seja, que busca compreender o ser humano dentro do seu contexto sócio histórico. Este estudo identificou, analisou e comentou como o indivíduo nas organizações interage com o outro para atingir seus objetivos fazendo uso de máscaras sociais. A transição de como esse trabalho ocorre e o benefício por ele produzido ajudou o indivíduo a formar sua identidade. Assim, a partir da abordagem da identidade dos indivíduos na cultura organizacional e o uso de máscaras sociais, foram extraídas reflexões, que ampliaram as discussões acerca dos recursos que o indivíduo utilizou para ser inserido nos grupos sociais.

Palavras-chave: Organização, Identidade, indivíduo, máscaras sociais. 


\begin{abstract}
The objetive of this research was to investigate social Masks: A reflection on the possible resources that the individual uses to protect its identity in the organizational context. The methodology was the separation and analysis of scientific articles. The research presented here is bibliographical. The proposal was a qualitative research, within a psychosocial approach, ie, that seeks to understand the human being within its socio-historical context. This study identified, analyzed and commented on how the individual interacts with other organizations to achieve their goals makes use of social masks. The transition occurs and how this work be produced helped benefit the individual to shape his identity. Thus, from the approach of the identity of individuals in organizational culture and the use of social masks, reflections were extracted, which broadened the discussions about the resources that the person used to be inserted in social groups.
\end{abstract}

Keywords: Organization, Identity, Individual, Social Masks.

\section{Introducción.}

O objetivo da pesquisa é propor uma reflexão sobre a personalidade representada pela máscara corporativa, utilizada pelo trabalhador na organização. A representação não retrata $\mathrm{O}$ indivíduo na sua essência, mas o apresenta ao outro, e ao mundo. Esta máscara pode servir de defesa ou ataque, com a finalidade de evitar que o indivíduo seja invadido pelo mundo exterior. As pessoas passam a maior parte do seu empo de vida na empresa - o seu local de trabalho, o que impacta a vida. as empresas não funcionam por si mesmas, elas precisam de pessoas para dirigi-las e fazê-las funcionar.

A pesquisa bibliográfica, eletrônica e de campo com observação in loco, a analise conectando literatura e realidade será feita em empresas. As ferramentas metodológicas para coleta, analise e interpretação de dados, o método qualitativo e quantitativo será auxiliado por instrumentos estatísticos. Estes permitirão mensurar o percentual de in/satifação, verificar média, desvio-padrão, coeficiente de correlação, análise de regressão, escolhidas para compreender esse indivíduo que ingressa na empresa. Ele carrega consigo objetivos de atingir sucesso pessoal e organizacional, divergentes dos objetivos da empresa, que é atingir, por meio do contratado, o sucesso empresarial. A metodologia, engloba dois momentos distintos.

A justificativa é que a empresa não existe sem o homem, pois ele é que a compõe, e o homem não vive sem a empresa, pois é nela que ele se realiza. No espaço corporativo ele se sente recompensado e alimenta o seu sentimento de competência, reconhecimento e fortalece a sua autoestima.

A hipótese é que quando o operário não atinge os seus os objetivos, ocorre a frustração. Frustrado o indivíduo não apresenta motivado a desempenhar bem o seu papel profissional. Este comportamento impede que ambos atinjam as suas propostas. Para que isso seja evitado, a empresa proporciona treinamento e incute na 
mente do funcionário um modelo comportamental adequado a sua cultura organizacional que, por meio de estímulos e reforço positivo, possibilita aos dois atingir os seus objetivos.

Pensando nesta afirmação de Souza (2015) se definiu o referencial teórico. Eibesfeldt (1973) tece considerações sobre os recursos que o indivíduo utiliza para proteger a identidade no contexto organizacional, é complexo e subjetivo visto por Bystrina (1995). Dejours (1992) tece a possibilidade do ser se auto compreender. As estratégias deste recurso, de acordo com Caillois, (1967:60) carrega opiniões por vezes contraditórias em função das regras do jogo da representação. $\mathrm{Na}$ organização o homem se compreende e se percebe como indivíduo e como grupo e se relaciona com a sua imagem persona. As representações impostas pelas máscaras carregam os seus valores socialmente estabelecidos e por meio do cargo, se impor e/ou se proteger. Neste espaço, supõe-se aceito temporariamente de um ponto de vista fictício, uma ilusão permitida. Ali o homem vive um personagem e se conduz como tal personagem. [...] Ele é um simulacro, pois, se encontra diante de situações nas quais se faz acreditar e faz outros acreditarem que ele é outro que não ele mesmo - chefe, colega, responsável, importante. [...] Ele foge da realidade para um outro mundo e se faz passar por outro (CAILLOIS, 1967:60).

Segundo Lakatos e Marconi (2010), além dos métodos específicos das Ciências Sociais, como o de Abordagem e o de Procedimento, o método Qualitativo e o método Quantitativo também são muito importantes nas investigações científicas.

Além disso, Lakatos e Marconi (2010) também afirmam que a forma de coleta e a análise de dados também diferem. "No método quantitativo, os pesquisadores valem-se de amostras amplas e de informações numéricas, enquanto que no qualitativo as amostras são reduzidas, os dados são analisados em seu psicossocial e os instrumentos de coleta não são estruturados" (LAKATOS; MARCONI, 2010, p. 269). A organização é um espaço de conflito em permanente busca da solução (SILVA; MENEZES, 2001, p.20).

Caillois, (1967:60). Aponta que do ponto de vista cientifico o indivíduo usa máscaras no contexto organizacional para ampliar as discussões. O uso simbólico de máscara permite identificar que toda atividade social é a representação de papéis nos quais as pessoas se conhecem e se reconhecem uns aos outros. A máscara passa a ser a própria identidade, ou seja, a percepção que se tem de si mesmo. O indivíduo constrói sua própria mascara e a torna verdadeira personagem que o identifica e que se traduz na construção de um estilo, a máscara que esconde a identidade e deixa mostrar aquilo que se pretende ser. A compreensão sobre o próprio ser é um fator importantíssimo para a tomada de decisões e em que momento deve-se tirar as máscaras.

O indivíduo no processo de interação com o outro na empresa, encena determinados papéis, no decorrer da interação social, os significados vão sendo modificados e integrados, 
já que esta busca geralmente acontece baseada em valores socialmente estabelecidos. Conforme Flusser (1996, p. 243),

"o gesto não é apenas articulação de uma interioridade.
Rebate sobre a interioridade e a transforma". Um
exemplo é nossa imaginação, que é fortalecida a cada
vez que a complementamos e a alimentamos. Desta
maneira, ela vai se tornando cada vez mais forte e, por
isso, dá novos significados às dúvidas que temos sobre
nós e sobre o ambiente em que interagimos, da mesma
forma a relação entre objeto e pessoa (FLUSSER,
1996, p.64).

Falar de imagem social e identidade é falar de sentimentos e como a máscara passa a ser a nossa própria identidade, o nosso eu, com o qual nos esforçamos por parecer.

\section{As Organizações}

Segundo Chiavenato, (2004, p. 2) as organizações são constituídas de pessoas e são elas que tornam possível atingir seus objetivos e cumprir suas missões. A organização é um meio para alcançar seus objetivos pessoais, com um custo reduzido de tempo e esforço. As pessoas são diferentes entre si, possuem personalidade própria, história pessoal particular, dotadas de habilidades, conhecimentos e competências, pessoas como pessoas e não como simples recursos da organização. As pessoas são os elementos vivos impulsionadores da organização, possuem talento para o crescimento e desenvolvimento pessoal, é fonte de impulso próprio e não como agentes estáticos. As pessoas são os parceiros da organização, os únicos capazes de conduzi-la ao sucesso e excelência de acordo com Chiavenato (2004, P. 3).

$\mathrm{O}$ indivíduo através das organizações satisfaz diferentes tipos de necessidades: emocionais, espirituais, intelectuais, econômicas, entre outras. Desta forma as organizações são formadas por pessoas para superarem suas limitações individuais e trabalharem eficazmente em conjunto na opinião de Chiavenato (2004, P. 8).

Para Morim (2001) a organização é guiada pela mudança de comportamento do indivíduo, que aos poucos desenvolvem atitudes motivadoras, tendo suas funções executadas na empresa e para o empregador, sendo o comprometimento um sinalizador positivo de uma organização eficaz.

O comportamento das pessoas dentro da organização é complexo, depende de fatores internos decorrentes da sua personalidade, como capacidade de aprendizagem, motivação, percepção do ambiente interno e externo, suas atitudes, entre outros, e fatores externos decorrentes do ambiente que está inserido e das características da organização, como sistemas de recompensas e punições, fatores sociais de acordo com Chiavenato (2004, P. 50).

Refletindo sobre a colocação de Morim (2001), Souza, (2015, pp. 114 115) alerta que:

$$
\begin{aligned}
& \text {... o comportamento do trabalhador tanto é guiado } \\
& \text { quanto guia as mudanças organizacionais. A autora }
\end{aligned}
$$


chama atenção para os processos de aprendizagem organizacional que nada mais são que jogos de repetições - o que se traduz no processo de treinamento. A empresa utiliza sons e imagens quando estabelecem metas a serem atingidas pelos funcionários. Para vencer essas metas, o funcionário adota a identidade corporativa porque ela é imperativa para quem quer permanecer empregado. Tal procedimento exige esforço, pois os nômades precisam ficar surdos e insensiveis ao chamado de sua natureza andarilha, Flusser (1979) para se sedarem e representar. Eles re-significam os signos corporativos e os in/corporam para compor os papéis designados pela empresa e representá-los. Esse arranjo é possivel porque a representação de papéis foi apreendida e utilizada para se comunicarem quando da formação dos primeiros vínculos familiares conforme Harlow (1970). A comunicação organizacional - as normas - utiliza os processos comunicacionais a partir do núcleo familiar, que segundo Eibesfeldt (1973:179), representam o primeiro espaço em que se criam vínculos e se contribui para mantê-los. Estabelecem os primeiros elementos de limites sociais, demarcam espaços para as primeiras formas de sociabilidade, agregam, reúnem, cuidam da união das pessoas e inter-relacionamento. Pross (1980:37) lembra que a simbolização é uma necessidade do homem, já que "vive representando signos e existe através deles". Essa representação é aprendida na comunicação familiar, primeiro núcleo onde é experimentado este ato complexo de aprendizagem que socializa e adapta, para repetir posteriormente nos demais espaços existenciais - isso constitui a idiossincrasia - forma de ver pensar e sentir o mundo, a partir das experiências vividas. Para atingir os seus objetivos, as instituiçoes assumem a tarefa de treinar, desenvolver, medir a aprendizagem, controlar e corrigir, o corpo funcional através de dispositivos disciplinares "premiação e punição" (Foucault, 2002:165) pelo papel que representa no cargo.
As articulações do sistema simbólico e do real na relação dos homens com a empresa" definem o comportamento desejado.

Compreende-se que toda pessoa tem necessidades que variam de pessoa para pessoa, influenciando em diferentes padrões de comportamento. A satisfação das suas necessidades são os motivos do seu comportamento e reside no próprio indivíduo. Cada indivíduo tem seu tempo e sua forma de se saciar enquanto indivíduo, portanto a motivação de cada um é individual e carregada de características únicas fazendo com que este indivíduo tenha sua própria vontade e desejo levando a ter determinado comportamento em alguma situação pela qual estiver passando.

O trabalho pode ser uma fonte de prazer ou não, pode estar associado ou não a trocas visando o financeiro, seria uma atividade útil, com objetivo que vai além de ser agradável ou desagradável. Quanto ao emprego Morim (2001) explica que é a ocupação de um indivíduo dentro da organização, que corresponde a um conjunto de atividades remuneradas, implica quase sempre na noção de salário e no consentimento de realizar atividades ditadas por outra pessoa. Entende-se que na realização de uma atividade, de um trabalho o indivíduo possa produzir algo útil, buscando por uma satisfação pessoal, o emprego nos parece ser algo imposto, condicionando sua realização com o pagamento pelo mesmo.

O modo como os indivíduos trabalham e o que eles produzem, causa impacto sobre o que pensam e como percebem sua liberdade e 
independência, a transição de como esse trabalho ocorre e o benefício por ele produzido ajuda o indivíduo a formar sua identidade Os indivíduos vão criando sua identidade a partir do momento que experimentam e conseguem ter oportunidades na vida, portanto, a identidade de cada um vai diferir do outro de acordo com as experiências de vida e o uso devido da informação transformada em conhecimento para ser utilizada no dia a dia.

Segundo Morim (2001) um trabalho com significado é aquele que diz respeito à personalidade, aos talentos e aos desejos do indivíduo. $\mathrm{O}$ trabalho permite realização pessoal, dando oportunidades para vencer desafios e obstáculos. Pessoas que trabalham no que gostam sentem prazer no que fazem e tem a tendência de realizar um trabalho melhor com qualidade, pois querem aprimorar cada vez mais seus resultados buscando a perfeição.

As organizações não funcionam sozinhas, dependem de pessoas para dirigi-las, controlá-las, visando seu sucesso. Cada pessoa tem sua própria característica de personalidade, suas aspirações, seus valores, suas atitudes, suas motivações, entre outras, todos são influenciados por variáveis dentro desse contexto organizacional Chiavenato (2004, p. 48).

Quando o indivíduo entra na organização ele tem seus sonhos e pretende atendê-los. Mas, as empresas têm o seu projeto para aquele funcionário funcionar e tem para ele um projeto. Ambos vão representar um papel e ambos vão procurar atingir o seu objetivo. No caso do funcionário ele usa uma máscara para suportar a relação na qual procura atingir os seus objetivos e levar a empresa a atingir os dela.

Quando o trabalhador colocar a sua máscara ele:

Paga o preço afastando-se dos seus próprios valores e da percepção de si mesmo, incorporando a empresa. Caillois (1967) explica que nesse mecanismo o bomem se traveste do papel que representa e disfarça a sua personalidade, pois adquire outra incorporada pela missão organizacional. $A ̀$ atividade de submissão continua às regras do jogo o autor chama de Mimicry on mimetismo, pois nessa relação o homem disfarça a sua personalidade e incorpora a da empresa representando os seus papéis. Lança mão do artifício da máscara que lhe permite a mudança da aparência - uniforme - $e$ dessa forma, ocupa ai um lugar, como ocorre no jogo, ele se mascara e se traveste de outro que não é ele mesmo. Aqui se fundem os conceitos apontados por Pross (1980), Bystrina (1995) e Foucault (1990), Dejours (1992) e Caillois (1967). No percurso da análise podese observar que os adeptos mudaram a estrutura dos seus vínculos, os novos vínculos passaram a carregar em si características dos antigos, houve uma dupla contaminação, homem e empresa. O funcionário se depara com o conflito de não ser ele mesmo nem o outro e se perde, (Sfez, 1994). O comportamento resultante desse distúrbio dissimulador e que prometia ser perfeito custa ao funcionário um esforço psíquico do comprometimento acima de tudo. As normas, a filosofia $e$ as políticas da empresa prometem atender a todas as expectativas pessoais e profissionais do funcionário proporcionando-lhe a felicidade e na esperança de ser feliz, ele se alienado, e ai se queda insano. Os funcionários da empresa pesquisada a acreditam na promessa (SOUZA, pp 120 - 121). 
Enquanto o funcionário acreditar que a empresa possibilitará a sua realização como pessoa e profissional ele se dedicará e levará a empresa a realizar os objetivos dela. Compreende-se que nesse contexto social a competição provocada pela evolução tecnológica nos últimos anos e o cenário global de constantes mudanças provocou transformações nos modelos organizacionais, mas o comprometimento mantém a recurso da máscara. Todas essas mudanças são fundamentais e acontecem tanto no ambiente externo como no contexto interno das organizações. Com o desenvolvimento global a necessidade de se travestir aumentou porque o funcionário passou a ser muito mais exigido.

A globalização fez com que as pessoas se preparassem mais para serem mais competitivos no mercado de trabalho. Esse processo contemporâneo força as pessoas estudarem mais, se aperfeiçoarem por meio de cursos atualizadores onde buscam mais informações para transformá-las em diferencial competitivo. Angariam conhecimento, e aperfeiçoam a arte de substituir várias máscaras. Um permanente ator em cena trocando de máscaras e personagens

\section{A Competividade Nas Organizações}

Além da exigência de maior escolaridade e da necessidade de multifuncionalidade, os trabalhadores passaram a sentir a necessidade cada vez maior de se prepararem para o mundo onde as palavras que se destacam são: flexibilidade e agilidade, criatividade e competência, trabalho em grupo e alto grau de compromisso. As mudanças têm ocorrido de forma rápida e cabe aos profissionais das empresas acompanharem essas alterações conforme Dutra (1996) e

Segundo Boog (1999), a competência é amola que move a empresa, o dinheiro é o motivador das pessoas onde prevalece primeiro o eu, depois o grupo, e um bom gerente deve ser, antes de tudo, um bom técnico, muito eficiente, com estilo centralizado, diretivo e que não delega poder.

A aprendizagem é caracterizada por assimilação do conteúdo, que nada mais é que uma internalização transformada em conhecimento. Esse conhecimento será aplicado ou praticado pelo indivíduo e agregará nova informação àquela que já foi aprendida e será acomodada, dando origem a um novo processo. Dessa maneira, a aprendizagem pode ser contínua, desde que haja interesse por parte do indivíduo e que essas novas informações façam significado com o que ele já aprendeu, é um processo constante.

$$
\text { Conforme Dilworth (apud }
$$
MARQUARDT, 2005, p.118), o aprendizado decorrente de um programa de aprendizagem pela ação tem maior valor estratégico para a organização do que a vantagem tática imediata de resolver um problema.

A aprendizagem em uma equipe depende muito das relações existentes entre os indivíduos, depende da confiança que um tem 
no outro, assim como da forma que a informação é passada entre os indivíduos. A confiança e a maneira de experimentar as formas de se conseguir resultados na prática propiciam uma maneira de aprender, experimentar e agregar valor ao que se já sabe. De acordo com Marquardt (2005, p.119), “o grau e a qualidade da aprendizagem não são inesperados, porque se desenvolvem por meio de pessoas reais que trabalham umas com outras em problemas reais, buscando um conhecimento que provocará uma mudança positiva.

A aprendizagem se dá nessas equipes de forma colaborativa e participativa. Cada um está preocupado com o resultado e, para que isso ocorra, cada fase e cada indivíduo devem buscar a melhor maneira de executar suas tarefas. A participação dos outros pares se torna importante à medida que podem contribuir de forma significativa com informações compartilhadas na equipe. A competitividade exigida pelas organizações, nos dias de hoje, fez com que as maquinas substituísse muitos trabalhos dentro delas. Porém, o que torna a empresa competitiva é o que ela consegue fazer de diferente, de forma exclusiva. A constante inovação depende das pessoas que trabalham nas organizações. Esse capital humano é a soma dos conhecimentos, das habilidades e capacidades das pessoas que geram valor econômico para a empresa na concepção de Pontes (2005).

É por isso que a relação entre a empresa e o funcionário deve ser uma relação de troca. A empresa precisa responder às expectativas de seu colaborador para que este corresponda às expectativas da empresa. Ele deve sentir-se constantemente valorizado, pois sua carreira e seu sucesso andam de mãos dadas com os interesses da organização. Compreendemos que para uma organização possa introduzir novos produtos, os trabalhadores devem estar motivados e treinados para tanto. Somente o indivíduo motivado estará disposto a se comprometer com os objetivos da empresa. Motivar os empregados é certamente uma difícil missão para os gestores em geral, diz Tachizawa (2004), é um fator que parece revestir-se de grande importância, é a qualidade da liderança exercida. Diante de tantas transformações o indivíduo e o meio o qual é inserido foi sendo modificado, marcado pelos acontecimentos. $\mathrm{O}$ indivíduo pós-moderno precisou rever sua identidade, rever conceitos e principalmente sua posição no mundo. Precisou dar significado a todas essas novidades.

Diante deste cenário esse indivíduo tem sua identidade mascarada por outra que se adapte ao contexto social. Levy (1996, p. 33) diz que a máscara protege a identidade do indivíduo e possibilita a exposição das ideias, vontades e desejos, que não poderia expressar fazendo uso da própria identidade. Não se discute, aqui, se esse anonimato ou uma falsa identidade são utilizados para o bem ou o mal. A possibilidade de se adotar múltiplas identidades é uma possibilidade desse indivíduo se inserir nesse contexto. 
No que diz respeito às organizações, diz Robbins (2002), as incertezas do mundo moderno limitam sua capacidade de prever necessidades, diminuindo sua responsabilidade pelo desenvolvimento profissional de seus colaboradores. Entretanto as organizações podem e devem orientá-los e estimulá-los a desenvolver sua própria identidade e competência, lidando com o diferente e o novo. As emoções são parte de nossas vidas e as pessoas carregam um componente emocional com elas para o trabalho todos os dias. As emoções são essenciais para construir uma ponte vigorosa entre o indivíduo e o trabalho. Sem emoção, não há envolvimento nem energia para a ação (ROBBINS, 2002).

O trabalho é uma atividade que coloca as pessoas em contato umas com as outras, contribuindo para o crescimento da identidade delas, um trabalho que tem sentido permite colaborar com os outros, ajudarem a resolver seus problemas, ser reconhecido por suas habilidades. Compreendemos que esse contato age como um estimulante para si mesmo, para o desenvolvimento de sua identidade pessoal e social e para o desenvolvimento de relações duráveis, contribuindo para a sua relação no contexto social para Morim (2001).

\section{A Identidade Dos Indivíduos $\mathrm{Na}$ Cultura Organizacional}

O conceito de identidade para Jacques (1999, p. 161) diz respeito à imagem, representação e conceito de si; referem-se a um conjunto de traços, de imagens, de sentimentos que o indivíduo reconhece como fazendo parte dele próprio. A identidade pode ser representada pelo nome e ou por outras denominações como as referentes ao papel social. $\mathrm{Na}$ representação de si através da qual é possível apreender a identidade é sempre a representação de um objeto ausente (o si mesmo). Desta forma, a identidade se refere a um conjunto de representações que respondem a pergunta quem és. $\mathrm{O}$ vocábulo de identidade se define tanto como qualidade do que é idêntico, igual, como a noção de um conjunto de caracteres que fazem reconhecer um indivíduo como diferente dos demais diz Jacques (1999, p. 164).

Compreendemos que mesmo isolado o indivíduo se constitui através do outro, como exemplo, modelo ou concorrente. Silva e Nogueira (2001) apud Erikson a identidade é vista como pessoal e cultural, somente dentro de um grupo o indivíduo pode se tornar um ser verdadeiro e autêntico. $\mathrm{O}$ indivíduo mesmo isolado precisa fazer parte de um grupo para satisfazer seus desejos e objetivos. A realidade do indivíduo é construída através da sua percepção do mundo, como crenças, valores, entre outros. Esta construção permite que o indivíduo na organização compartilhe com outros integrantes normas e valores que são tidas como certas no contexto organizacional.

Ao ser contratado para exercer determinado cargo na empresa, o indivíduo se une com outros indivíduos para atuarem dentro de um mesmo sistema sociocultural. Essa união provoca a troca de crenças, valores, hábitos, 
entre outros, que irão conduzir suas ações dento de um contexto preexistente, delineando sua identidade. Entende-se que na construção de sua identidade o indivíduo utiliza valores que já possui em comparação com os valores que identifica no seu processo de socialização que ocorre na organização. O seu modo de ser, os papeis que representa em diferentes momentos da sua experiência social, permite tramitar entre os grupos sociais de que faz parte, tornando-se uma pessoa mutável.

Não tem sentido falar em uma única identidade dos indivíduos, mas em varias identidades que se constroem ao longo do tempo e nos diferentes contextos ou espaços dos quais esses indivíduos participam. De acordo com os mesmos autores, Silva e Vergara (2000, p. 5) falar de construção de identidade é compartilhar culturas em comum, seja no nível dos indivíduos, dos grupos ou da organização como um todo. A cultura organizacional representada como o alicerce para a formação da identidade dos indivíduos nas organizações.

Não se pode pensar a noção de identidade, se não for a partir da interação com outras pessoas, a identidade é construída de acordo com o ambiente em que está envolvido como, estruturas sociais, a cultura, o histórico das relações, entre outros. Schein (2001) nos diz que a cultura de uma organização pode ser aprendida nos níveis dos artefatos visíveis, ou seja, a forma como as pessoas se vestem, se comunicam, entre outros; o nível dos valores que governam o comportamento das pessoas, sendo os mais difíceis de serem identificados, pois são valores que levam as pessoas a agirem de diferentes formas; e por ultimo o nível dos pressupostos inconscientes, sendo os que determinam como indivíduos de um grupo percebem, pensa e sente.

Segundo os autores Fernandes e Zanelli (2006) quando a pessoa se define como indivíduo, tende a ativar uma orientação para a identidade pessoal, ou seja, como eu me vejo e me percebo, já a identidade social diz respeito aos conceitos que o indivíduo desenvolve de si na relação com o outro. Entende-se que o indivíduo tem a necessidade de ser reconhecido pelo grupo, pois a partir deste reconhecimento ele forma sua própria imagem, o grupo é um referencial para a formação da identidade social do indivíduo. A identidade é uma busca constante por parte dos indivíduos, pois adotam padrões comportamentais para preencher as expectativas do outro sobre seu próprio comportamento, contrariando sua autodeterminação.

$\mathrm{Na}$ construção da própria identidade é um desafio encontrar o equilíbrio entre aquilo que se é e o que os outros esperam que nós sejamos. O outro é o espelho social que permite ao indivíduo reconhecer-se, avaliar-se e aprovarse. O eu, só existe, na interação com os outros, na concepção de Machado (2003). Agir e interagir são formas importantes de analisar a identidade organizacional, realizar e pertencer são condições fundamentais para que os processos de identificação gerem estímulos, 
novas descobertas e formas de realizar atividades no contexto organizacional. Entende-se que o trabalho e a organização passam a ser as bases centrais de representação do eu para o indivíduo, ou seja, quanto maior o reconhecimento do indivíduo no trabalho ou no grupo, maior é à força desses elementos na construção de si.

Para construir uma identidade, o indivíduo precisa formular um significado do mundo, para finalmente se ver como alguém e ocupar um lugar nele. Para interagir com esse ambiente diversificado, múltiplo e instável, o novo indivíduo social precisa desenvolver modos de inserção nesse espaço, seja expondose ou por meio de máscaras. Vejamos mais a esse respeito no próximo item.

\section{Máscaras Sociais E Identidade}

Quando falamos em máscaras, pensamos em um objeto artístico colocado no rosto para esconder a identidade de uma pessoa. Segundo Canevacci (1990) vários são os significados que podem ser atribuídos à palavra máscara, confundindo-se, por vezes, com a função a ela atribuída. Como disfarce ou aparência enganadora; artefato que representa um rosto ou parte dele; objeto que destina a cobrir o rosto ou disfarçar o rosto de quem o utiliza.

No Brasil, a máscara é presença constante no carnaval, em festas populares e folclóricas e algumas culturas indígenas existentes. O folclore utiliza a fantasia e a máscara, promovendo a imaginação e os desejos dos sujeitos. No carnaval, no teatro e nas danças, as máscaras determinam o caráter dos seus personagens. Para Gama (2005), o indivíduo na sua interação com o outro desenvolve mais do que um personagem, podendo o indivíduo encenar um papel conforme se apresente num contexto social. Ele tem vários personagens, não dispensando nenhum deles. Nesta situação o eu é estritamente social. É diante do outro, a partir das respostas do outro em relação a si mesmo, que o indivíduo se constitui. $\mathrm{Na}$ relação social com o outro, o indivíduo possui um conjunto de máscaras que utiliza conforme o tipo de público que se apresente em determinado momento.

A interação social surge na relação de expectativas entre aquilo que o indivíduo pensa ser, aquilo que os outros esperam dele e aquilo que os outros pensam dele. A partir do momento que o indivíduo assume a imagem de si mesmo, que consegue mostrar a própria face, ele inicia um processo de aceitar-se como é. Na empresa um indivíduo primeiro protege a própria imagem, depois protege a imagem do outro. Diante desta situação o indivíduo desenvolve práticas defensivas e protetoras, ao proteger a imagem do outro evita perder a sua própria imagem, e ao proteger a sua própria imagem evita que o outro a perca na opinião de Gama (2005).

No contexto organizacional os funcionários constituem-se através dos encontros sociais e do controle de cada indivíduo sobre a ideia de si e dos outros, buscando adaptar sua postura às expectativas decorrentes dos papéis estabelecidos 
socialmente. Os conceitos impostos socialmente e o que cada indivíduo pode em determinada situação mostra que ele precisa fazer um esforço para que a sua máscara não lhe caia. $\mathrm{O}$ seu personagem é capaz de manter a capa da convencionalidade que mostra sua aceitação de valores com os quais todos os outros se conformam, ainda que de forma superficial. Persona é a raiz da palavra personalidade. Em latim, a máscara recebeu o nome de persona. $\mathrm{O}$ homem faz uso das máscaras através de uma identidade psíquica com o personagem existente no mito e no simbólico. $O$ homem na modernidade tem a necessidade de incorporar outras personalidades, para isso faz uso de máscaras sociais diz Jung (1964).

Zamperetti (2010) afirma que existe uma relação entre a máscara e a identidade do indivíduo, por vezes a máscara oculta uma personalidade, fazendo uso de um personagem, outras vezes a máscara mostra uma personalidade oculta. A máscara é um objeto transformador de quem usa e de quem a faz. Ciampa (1984) cita que são os personagens que montam suas histórias, dentro de uma sociedade onde fazem parte as pessoas com quem se convive, ou seja, "somos autores e personagens ao mesmo tempo" moldamos quem somos ou quem gostaríamos de ser. Temos a possibilidade de nos mostrarmos aos outros, de nos reconhecermos, o que não ocorre de forma global ou transparente, existe uma impossibilidade de dizer quem somos. Podemos nos esconder neste personagem, ou nos revelarmos pelo que ocultou. A identidade é mostrada aos outros como uma descrição de um personagem.

No contexto organizacional muitas vezes os indivíduos não têm uma forma definida, ela pode se modificar conforme a situação vivida. A identidade poderá ser vista como uma totalidade, que poderá depender de vários fatores, ser contraditória, sofrer mudanças, no entanto ela é única. E quando esta identidade aparece ameaçada, a pessoa tem horror em pensar na possibilidade de ser outro. Para Berger e Luckman apud Giordani (2006), a identidade é produzida na relação dialética entre indivíduo e a sociedade.

\section{Considerações Finais}

Como se pode observar falar sobre o ser humano é uma tarefa difícil, pois o mesmo se concebe constantemente, não é algo pronto e acabado, está sempre se constituindo. O tema Máscaras Sociais: Uma reflexão sobre os possíveis recursos que o indivíduo utiliza para proteger sua identidade no contexto organizacional nasceu de uma discussão em sala aula e da minha percepção no comportamento dos alunos da pós-graduação. Percebe-se o quanto muitos desses alunos seis meses depois se mostravam mais reservados e menos receptivos, um comportamento bem diferente do início do curso, onde todos eram amigos, compartilhavam experiências e vivências. 
Neste foi promovida uma reflexão sobre a identidade do individuo no contexto organizacional, e como sua forma de agir e interagir delineia sua identidade. Os desafios, as metas e seus objetivos são delineadores no processo de realizar e pertencer ao contexto organizacional, a partir do seu reconhecimento será despertado estímulos para seu processo de aceitação nesse grupo. A não aceitação nesse grupo promove muitas vezes a apropriação de outra identidade, fazendo uso de máscaras, e por máscaras entendemos ser um objeto usado para cobrir o rosto e disfarçar a pessoa que o põe.

A identidade é própria da construção do sujeito. Ela traz o desejo de existir e de ser reconhecido, e a necessidade de identificação com o outro. Identidade é um sentimento que o individuo aprende pelas representações que faz de si em relação aos outros. Ela nos permite observar que há no individuo um espaço interior e um olhar exterior. A imagem que construímos de nós mesmos é baseada naquilo que vemos e apropriamos diante do outro. Através do encaixe social o individuo vai modificando seu comportamento e valorizando aspectos da sua identidade. A imitação social, a simpatia e antipatia são modificações comportamentais para adequar-se às exigências sociais. O ideal é o aspecto subjetivo, importante em todas as esferas motivacionais e comportamentais (FERRAZ APUD PORTINARI, 2000).

Não se enquadrar ao padrão social préestabelecido pode ser motivo de angústia e tristeza. Desta forma o ideal e o real acabam sendo distantes, e o individuo se perde na sua própria imagem diz Ferraz (2007). O uso dessa máscara muitas vezes impede o verdadeiro contato com o outro, mas no contexto organizacional, onde a disputa pelo poder é constante pode muitas vezes dar ao indivíduo segurança e proteção para se colocar, ser inserido ao grupo. Tentar esconder a sua verdadeira identidade, pode muitas vezes ser insegurança e medo de não agradar ao outro, de decepcioná-lo.

Fazer uso dessa máscara é um recurso, é uma forma de mostrar o que outro quer que eu seja, o que o outro quer ver, ou seja, mostrar o que considero bom e atrativo para o outro. $\mathrm{O}$ eu em um contexto social, não deixa de ser uma de nossas máscaras, muitas vezes necessárias. Como se observou, ao longo desse artigo e através de pesquisa bibliográfica na literatura especializada, existe um consenso dos autores no que se refere o uso de máscaras pelo indivíduo dentro do contexto organizacional. O objetivo deste artigo foi o de levar ao leitor uma reflexão sobre o cuidado não apenas na utilização de máscaras, mas no seu uso constante e frequente, pois o seu uso é muitas vezes inconsciente e pode levá-lo a uma perda da própria identidade, como por exemplo, deixar de ser quem é realmente.

Os personagens adquiridos pelo indivíduo não devem se opor ou sublimar o eu real, a verdadeira identidade. Quando a máscara é mais "real" que o eu, o indivíduo perde sua identidade, se tornando superficialidade de um papel social. A pesquisa em seu percurso te a hipótese confirmada, se o indivíduo faz uso da máscara para proteger-se e se sentir inserido no 
contexto organizacional, este artifício mantém o seu eu adormecido durante o seu trabalho na empresa, levando-o a agir alienado de si mesmo, e neste espaço se dedica integralmente a atender os objetivos organizacionais.

A construção deste estudo permitiu um olhar reflexivo na necessidade de sobrevivência dentro de um sistema desconhecido, a identidade vista como um fenômeno social é constituído pelos diversos grupos de que fazemos parte, através das relações com o outro. O conceito de identidade nas organizações acontece da interação com o outro, construído e modificado pelas características organizacionais.

Ao analisar a identidade do individuo no contexto organizacional consideramos que o agir e interagir dão significados às identidades. A todo instante realizar e pertencer são elementos necessários para gerar estímulos, novas descobertas, transformando o ambiente organizacional a qual o indivíduo está inserido. Desse modo, o grupo, o trabalho e organização são peças fundamentais na representação do eu para o indivíduo. No contexto organizacional o sentimento de identificação do indivíduo com a organização atua como inspiração que tende a contribuir para a criatividade no trabalho e o seu desenvolvimento pessoal e social.

O vocábulo identidade evoca tanto a qualidade do que é idêntico, igual, como a noção de um conjunto de caracteres que fazem reconhecer um individuo como diferente do outro. A identidade de uma pessoa pode ser assimilada a partir do conhecimento dos grupos aos qual o indivíduo pertence. A identidade facilita o convívio, a organização e o controle social, garantindo certa estabilidade e permanência de um nível de conhecimento necessário dos outros para as relações cotidianas. Através do seu conhecimento, de suas habilidades e competências, o indivíduo pode vir a representar o diferencial no sucesso ou fracasso dos negócios das empresas.

Nesse sentido, podemos afirmar que este estudo contribuiu para uma reflexão ampliada em torno de um processo de construção de identidade pessoal e social, permitindo aos leitores um espaço onde poderão tomar conhecimento acerca dos conceitos aqui descritos. Este estudo não teve a pretensão de esgotar o assunto, mas sim salientar alguns pontos importantes de estudo no cenário empresarial e para pesquisa futura. As limitações impostas à pesquisa impediram a exploração de outras questões relevantes, provocando, dessa forma, a realização de novos trabalhos. 
Referências Bibliográficas e Eletrônicas

BERGER, P. LUCKMANN, T. (1989). A construção social da Realidade. São Paulo: Vozes.

BOOG, G. G. Manual de Treinamento e Desenvolvimento- ABTD- Associação Brasileira de treinamento e Desenvolvimento. 3ed. São Paulo: Makron Books, 1999. p. 1-13.

BYSTRINA, I. Tópicos de semiótica da cultura. São Paulo: CISC, 1995.

CANEVACCI, M. (1990) Antropologia da comunicação visual. São Paulo: Brasiliense.

CAILLOIS, Roger. Les jeux et lês hommes. Edtions Gallimard, (1958 1ª Ed.) 1967.

CIAMPA, A. C. Identidade. In: CODO, W. \& LANE, S.T.M. [et all], (organizadores). Psicologia Social: o homem em movimento. São Paulo: Editora Brasiliense, 1984.

CHIAVENATO, I. (2004) Introdução à teoria geral da administração: uma visão abrangente da moderna administração das organizações. Edição compacta. 3. ed. Rio de Janeiro: Elsevier. DEJOURS, C. A Loucura no trabalho: estudo de psicopatologia do trabalho. São Paulo: Cortez, O. 5a . ed, 1992.

DUTRA, J. S. Administração de Carreiras. São Paulo: Atlas, 1996. P. 21-31.

EIBESFELDT, Eibl. El hombre pré programado. Spain: Ed. Alianza, 1973. EIBESFELDT
FERNANDES, K. R.; ZANELLI, J. C. O processo de construção e reconstrução das identidades dos indivíduos nas organizações Online version ISSN 1982-7849 Rev. adm. contemp. vol.10 no.1 Curitiba jan./mar. 2006 http://dx.doi.org/10.1590/S1415-

65552006000100004 .

FLUSSER, V. A Dúvida. Rio de Janeiro: Relume Dumará, 1999.

. A História do Diabo. São Paulo: Martins Fontes, 1965.

Da religiosidade. São Paulo: Comissão Estadual de Cultura, 1967.

Ficções Filosóficas. São Paulo: Editora da Universidade de São Paulo, 1998.

Filosofia da Caixa Preta: ensaios para uma futura filosofia da fotografia. Rio de Janeiro: R Dumará, 1985.

Língua e realidade. São Paulo: Herder, 1963.

Los gestos: fenomenología y comuniación. Barcelona: Herder, 1994.

- Natural:mente: Vários acessos ao significado da natureza. São Paulo. Ed. Duas Cidades, 1979.

. Pós-história: vinte instantâneos e um modo de usar. São Paulo: Duas cidades, 1983.

FLUSSER, Vilém. "Texto / imagem enquanto dinâmica do Ocidente". In Cadernos Rioarte, Rio de Janeiro, ano II, n.5, jan., 1996.

FOUCAULT, M. História da loucura. São Paulo: Ed. Perspectiva, 2002. 
GAMA, M. G. A fabricação da Imagem Social da Empresa. Livro de Atlas $4^{\circ}$ SOPCOM Universidade do Minho, 2005. Acesso 21/03/ 2012 as 23:00 horas.

HARLOW, Harry. Love created, love destroied, love regained. In:modeles animaux du comportement humanin. Paris. Centre National de la RechercheScientifique, 1970.

JUNG, C. G. (org). O homem e seus símbolos. Rio de Janeiro. Nova Fronteira, 316 p. 1964.

LAKATOS, E. M.; MARCONI, M. A. Fundamentos de Metodologia Científica. São Paulo: Atlas, 2010.

LÉVY, Pierre. O que é o virtual? São Paulo: Ed. 34, 1996.

MACHADO, H. V. A identidade e o contexto organizacional: perspectivas de análise. Rev. adm. contemp. vol.7 no.spe Curitiba 2003 http://dx.doi.org/10.1590/S1415-65552003000 500004 ISSN 1982-7849.

MARQUARDT, M. J. O poder da aprendizagem pela ação: como solucionar problemas e desenvolver líderes em tempo real. Tradução Anna Lobo. Rio de Janeiro: Ed. Senac Rio, 2005.

MORIM, E. M. Os sentidos do trabalho. RAE Revista de Administração de Empresas/FGV/EAESP - jul./set. 2001 - São Paulo, v. 41 n3 p.8-19.

MOT'TA, F. C. P., \& VASCONCELOS, I. G. Teoria geral da administração. São Paulo: Pioneira Thomson Learning, 2002.
PONTES, B. R. A arte de selecionar talentos: planejamento, recrutamento e seleção por competência. São Paulo: DVS Editora, 2005.

PROSS, H. Estructura simbólica del poder. Barcelona: Gustavo GILI, 1980.

ROBBINS, S. P. Comportamento Organizacional. Tradução Reynaldo Marcondes. 9ed. São Paulo: Prentice Hall, 2002.

SCHEIN, E. H. Guia de sobrevivência da cultura coorporativa. (2th ed). Rio de Janeiro: José Olympio, 2001.

SFEZ, Lucien. Crítica da comunicação. São Paulo: Loyola, 1994:13. 124125

SILVA, J. R. G., \& VERGARA, S. C. (2000). O significado da mudança: as percepções dos funcionários de uma empresa brasileira diante da expectativa de privatização. Revista de Administração Pública, 34(1), 79-99.

SILVA, E. L. da; MENEZES, E. M. Metodologia da pesquisa e elaboração de dissertação. 3. ed. Florianópolis: UFSC, 2001.

SOUZA Monica Maria Martins de. http://cisc.org.br/portal/biblioteca/CISC 20 anos-Comunicacao Cultura e Midia.pdf. São Paulo 2015.

TACHIZAWA, T.; FERREIRA, V. C; FORTUNA, A. A. M. Gestão com pessoas uma abordagem aplicada ás estratégias de negócios. 4ed revistas e atualizada. Rio de Janeiro: FGV, 2004. P. 18-53. 
ZAMPERETTTI, M. P. (2010) A Arte e o Saber de si no uso pedagógico das máscaras - práticas e pesquisa na sala de aula - Revista Contrapontos

- Eletrônica, Vol. 10 - n. 1 - p. 65-73 / jan-abr 65. 